\title{
Increased glycemic variability associated with a poor 30-day functional outcome in acute intracerebral hemorrhage
}

\author{
Yan-Chun Wu, MD, ${ }^{1}$ Zan Ding, MD, ${ }^{2}$ Jiang Wu, MD, ${ }^{3}$ Yuan-Yuan Wang, MD, ${ }^{1}$ \\ Sheng-Chao Zhang, BS, ${ }^{3}$ Ye Wen, MD, ${ }^{2}$ Wen-Ya Dong, MD, ${ }^{2}$ and Qing-Ying Zhang, PhD ${ }^{2}$ \\ 1Department of Neurology Medicine and Surgery Services, First Affiliated Hospital of Shantou University Medical College, \\ Shantou; ${ }^{2}$ Department of Preventive Medicine, Shantou University Medical College, Shantou; and ${ }^{3}$ Community Health Service \\ Center, Shenzhen Baoan District Central Hospital, Shenzhen, Guangdong, People's Republic of China
}

\begin{abstract}
OBJECTIVE Intracerebral hemorrhage (ICH) is associated with a poor prognosis and high mortality, but no study has elucidated the association between glycemic variability (GV) and functional outcome in ICH. The authors of this study aimed to determine whether $\mathrm{GV}$ is a predictor of 30 -day functional outcome in $\mathrm{ICH}$ patients.

METHODS The study recruited 366 patients with first-ever acute-onset ICH in the period during 2014 and 2015. Fasting blood glucose was assessed on admission and with 7-day continuous monitoring. Glycemic variability was calculated and expressed by the standard deviation $\left(\mathrm{Glu}_{\mathrm{sD}}\right)$ and coefficient of variation $\left(\mathrm{Glu}_{\mathrm{CV}}\right)$. Patients were divided into groups of those with diabetes mellitus (DM), stress hyperglycemia (SHG), and normal glucose (NG). Functional outcome was measured using the modified Rankin Scale.
\end{abstract}

RESULTS The numbers of patients with DM, SHG, and NG were 108 (29.5\%), 127 (34.7\%), and 131 (35.8\%), respectively. As compared with the DM patients, those with SHG had higher mortality $(29.9 \%$ vs $15.7 \%, p<0.05)$ and a poorer prognosis $(64.6 \%$ vs $52.8 \%, p<0.05)$. Poor prognosis was associated with both high $\mathrm{Glu}_{\mathrm{SD}}(\mathrm{OR} 1.54,95 \% \mathrm{Cl} 1.19-1.99)$ and high $\operatorname{Glu}_{\mathrm{cV}}(1.05,1.02-1.09)$, especially in the DM group. The area under the receiver operating characteristic curve was greater for the $\mathrm{Glu}_{\mathrm{SD}}(\mathrm{OR} 0.929,95 \% \mathrm{Cl} 0.902-0.956)$ and the $\mathrm{Glu}_{\mathrm{CV}}(0.932,0.906-0.958)$ model than the original model $(0.860,0.823-0.898)$ in predicting a poor outcome.

CONCLUSIONS Stress hyperglycemia may be associated with increased mortality and a poor outcome in ICH, and increased GV may be independently associated with a poor outcome, particularly in ICH patients with DM.

https://thejns.org/doi/abs/10.3171/2017.4.JNS162238

KEY WORDS glycemic variability; stress hyperglycemia; functional outcome; intracerebral hemorrhage; vascular disorders

$\mathrm{S}$ TROKE is the second leading cause of death worldwide and the first in China, and the absolute number of people with a first stroke, who are stroke survivors, who have stroke-related deaths, and who have disabilityadjusted life-years lost due to stroke has increased in the past 2 decades. ${ }^{11,40}$ Intracerebral hemorrhage $(\mathrm{ICH})$ is a serious disease, accounting for $10 \%-15 \%$ of stroke cases, and has a high case fatality rate of about $35 \%-50 \%$ as well as a poor prognosis, with only $10 \%-20 \%$ surviving and living independently at 30 days..$^{20,30}$ Risk factors for early death and a poor functional outcome in ICH include a low Glasgow Coma Scale (GCS) score at admission, large hematoma volume, intraventricular hematoma (IVH), and hypertension. ${ }^{15,23,26}$ Early intervention and management of these factors may ameliorate the poor prognosis in ICH.

Hyperglycemia is a common phenomenon in ICH patients and can be caused by diabetes mellitus (DM) or stress hyperglycemia (SHG). ${ }^{27}$ The latter disorder gener-

ABBREVIATIONS AUC $=$ area under the receiver operating characteristic curve; $C V=$ coefficient of variation; $D B P=$ diastolic blood pressure; $D M=$ diabetes mellitus; FBG = fasting blood glucose; GCS = Glasgow Coma Scale; $\mathrm{Glu}_{\mathrm{CV}}=$ coefficient of variation of glucose; $\mathrm{Glu}_{\mathrm{SD}}=$ standard deviation of glucose; $\mathrm{GV}=$ glycemic variability; $\mathrm{HbAlc}=$ glycosylated hemoglobin; HDL-C = high-density lipoprotein cholesterol; ICH = intracerebral hemorrhage; IVH = intraventricular hematoma; LDL-C = low-density lipoprotein cholesterol; MI = myocardial infarction; $\mathrm{mRS}=$ modified Rankin Scale; $\mathrm{NG}=$ normal glucose; $\mathrm{SBP}=$ systolic blood pressure; $\mathrm{SD}=$ standard deviation; $\mathrm{SHG}=$ stress hyperglycemia; $\mathrm{TC}=$ total cholesterol; $\mathrm{TG}=$ triglyceride; $\mathrm{WBC}=$ white blood cell.

SUBMITTED August 28, 2016. ACCEPTED April 4, 2017.

INCLUDE WHEN CITING Published online November 3, 2017; DOI: 10.3171/2017.4.JNS162238. 
ally refers to transient hyperglycemia in patients without previous evidence of DM. ${ }^{8}$ The measurement of glycosylated hemoglobin (HbAlc) has unique application value, and an HbAlc $\geq 6.5 \%$ is widely considered the gold standard for DM diagnosis. ${ }^{1}$ Many studies have investigated the effect of hyperglycemia on the prognosis of ICH but have not measured the HbAlc level to distinguish whether the hyperglycemia resulted from DM or SHG. ${ }^{2,14,32,33}$ The level of glucose in SHG can revert to normal but continues to be high in DM, so it must be accounted for in continuous glucose monitoring. No studies have observed the relationship between glycemic fluctuation and functional outcome in acute-onset ICH.

Recently, glycemic variability (GV), an important index of glycemic fluctuations measured with continuous glucose monitoring, has been implicated in the diseaseassociated process of dysglycemia. ${ }^{24}$ The standard deviation (SD) and coefficient of variation (CV) of the glucose value are considered strong independent indexes for determining GV, although the best method for characterizing $\mathrm{GV}$ in hospitalized patients has not been agreed on. ${ }^{29,31}$ Several studies have demonstrated high GV associated with significantly increased mortality in critically ill patients. ${ }^{9}, 19$ However, no study has reported on the association between GV and clinical outcomes in hospitalized patients, particularly those with acute-onset ICH.

In the present study we emphasize the importance of distinguishing between DM and SHG in hyperglycemia and the fasting blood glucose (FBG) level monitored for 7 continuous days. We evaluated the association of hyperglycemia in DM or SHG and GV as measured by continuous monitoring of FBG for 7 days with functional outcome at 30 days in acute-onset ICH.

\section{Methods \\ Study Participants}

We recruited 366 patients with first-ever acute-onset ICH who were admitted to the Department of Neurology Medicine and Surgery Services in the First Affiliated Hospital of Shantou University Medical College between January 1, 2014, and December 31, 2015. All patients were 18 years of age or older and were admitted to the hospital within 24 hours of the first symptoms of disease, with the diagnosis of ICH confirmed by CT or MRI studies. On the basis of ICH guidelines from the American Heart Association, clinical management was established at the discretion of the treating physician. ${ }^{17}$ Patients with pituitary tumors, hyperthyroidism, acute pancreatitis, and endocrine tumors that may cause hyperglycemia were excluded. Patients with traumatic hemorrhage or recurrent episodes of hemorrhage (for example, subarachnoid hemorrhage, brain tumor or hemorrhagic transformation of ischemic stroke, and subdural or extradural hemorrhage) were also excluded. This study was conducted according to guidelines in the Declaration of Helsinki, and all procedures involving humans were approved by the Ethics Committee of the First Affiliated Hospital of Shantou University Medical College. Written informed consent was obtained from all participants. The required sample size was determined by assuming an OR 1.5 for group comparison at the 5\% significance level; therefore, a sample size of 53 per group was needed to attain $90 \%$ power, as calculated by NCSS-PASS 2005 .

\section{Neuroradiological Methods}

From CT scans and MR images, we recorded hematoma location (basal ganglia, lobar, brainstem, cerebellum, or thalamus), presence of IVH, and hematoma volume (classified as $<20,20-40$, and $\geq 40 \mathrm{ml}$ ) measured using the $\mathrm{ABC} / 2$ method (A, greatest hemorrhage diameter; $\mathrm{B}$, diameter perpendicular to $\mathrm{A} ; \mathrm{C}$, number of slices multiplied by slice thickness).$^{18}$ Initial neurological deficit was determined using the GCS, usually used to assess coma and impaired consciousness; 34 GCS scores were classified as 13-15 (mild disability), 9-12 (moderate disability), and $\leq 8$ (severe disability). Functional outcome was measured using the modified Rankin Scale (mRS), ${ }^{4}$ scored by a designated neurologist to evaluate therapeutic effects and prognosis at 30 days after admission. The mRS scores were divided into good outcome $(\mathrm{mRS}$ score $<3)$ and poor outcome (mRS score $\geq 3$ ), with an mRS Score of 6 considered as death. ${ }^{39}$

\section{Medical Records}

Medical records were examined for previous diseases including myocardial infarction (MI), hypertension, and DM. Diagnosis of prior MI was based on the medical history of the patient. In accordance with the World Health Organization (WHO)/International Society of Hypertension statement, ${ }^{38}$ hypertension was diagnosed as blood pressure $\geq 140 / 90 \mathrm{~mm} \mathrm{Hg}$ measured at least twice or if a patient was taking antihypertensive medication. Diabetes mellitus was defined according to the criteria of the American Diabetes Association-that is, FBG $\geq 7.0$ $\mathrm{mmol} / \mathrm{L}$, random glucose $\geq 11.1 \mathrm{mmol} / \mathrm{L}$ measured at least twice, or HbAlc $\geq 6.5 \%$ - or as a history of DM (medical record of DM and/or taking insulin or oral hypoglycemic agents). ${ }^{1}$ Accordingly, all participants were divided into 3 groups: DM (history of DM or HbAlc $\geq 6.5 \%$ and FBG $\geq$ $7.0 \mathrm{mmol} / \mathrm{L}$ ), SHG (no history of DM, HbAlc $<6.5 \%$, and $\mathrm{FBG} \geq 7.0 \mathrm{mmol} / \mathrm{L}$ ), and normal glucose (NG; no history of DM, HbAlc $<6.5 \%$, and $\mathrm{FBG}<7.0 \mathrm{mmol} / \mathrm{L}$ ).

We collected venous blood from fasting patients at least 8 hours after ICH onset and at 5:00-6:00 each morning of the 7 consecutive days after admission. All examinations were performed in the clinical laboratory of the hospital. Fasting blood glucose was measured via the enzymatic method using an auto-analyzer (Beckman Coulter Inc.), and $\mathrm{HbAlc}$ was measured via the high-performance liquid chromatographic method using an automated glycohemoglobin analyzer (Tosoh Corp.).

Glycemic indices such as SD of 7-day FBG level $\left(\mathrm{Glu}_{\mathrm{SD}}\right)$ and $\mathrm{CV}$ of 7-day FBG level $\left(\mathrm{Glu}_{\mathrm{CV}}\right)$ were calculated; $\mathrm{Glu}_{\mathrm{CV}}$ was calculated using the equation $\mathrm{Glu}_{\mathrm{CV}}=$ $100 \% \times \mathrm{Glu}_{\mathrm{SD}} /($ mean glucose $) .{ }^{28}$ Patient age and sex, health habits (for example, smoking status, alcohol intake), systolic blood pressure (SBP), diastolic blood pressure (DBP), pulse pressure (calculated as SBP - SDP), white blood cell (WBC) count $\left(10^{9} / \mathrm{L}\right)$, total cholesterol (TC), low-density lipoprotein cholesterol (LDL-C), high-density lipoprotein 
cholesterol (HDL-C), and triglycerides (TG) at admission were also collected.

\section{Statistical Analysis}

Qualitative variables are expressed as frequencies (\%) and continuous variables as the mean \pm standard deviation. Continuous variables were analyzed for normality using the Kolmogorov-Smirnov test. Significant differences between groups were assessed with the Mann-Whitney U-test for skewed variables and Pearson's chi-square test with or without Bonferroni correction for categorical variables. Bivariate analysis was initially performed to identify a significant association between individual variables and 30-day functional outcome. Variables with a $\mathrm{p} \leq$ 0.05 on bivariate analysis were included in the multivariate model (that is, the original model). In the multivariate models, variables with a $\mathrm{p}<0.05$ were retained by forward logistic regression elimination. Odds ratios with $95 \%$ confidence intervals were calculated. We separately added $\mathrm{Glu}_{\mathrm{SD}}$ and $\mathrm{Glu}_{\mathrm{CV}}$ to the original model to create the $\mathrm{Glu}_{\mathrm{SD}}$ model and $\mathrm{Glu}_{\mathrm{CV}}$ models. We also analyzed the area under the receiver operating characteristic curve (AUC) to judge the discrimination ability of various statistical methods. ${ }^{16}$ Statistical analyses involved the use of SPSS for Windows 13.0 (SPSS Inc.) and R version 3.2.0 (R Foundation for Statistical Computing, http://www.R-project.org). Twotailed tests of significance were reported, with $\mathrm{p}<0.05$ considered statistically significant

\section{Results \\ Study Population}

A total of $366 \mathrm{ICH}$ patients were divided into 3 glucose groups, with 108 (29.5\%), 127 (34.7\%), and 131 (35.8\%) in the DM, SHG, and NG groups, respectively (Table 1). The rate of newly diagnosed $\mathrm{DM}$ on admission, according to an HbAlc level $\geq 6.5 \%$, was $15.3 \%$ (56/366). The variables hypertension, SBP, DBP, initial GCS score, hematoma volume, IVH, WBC count, TC, TG, admission FBG and HbAlc levels, $\mathrm{Glu}_{\mathrm{SD}}$, and $\mathrm{Glu}_{\mathrm{Cv}}$ all significantly differed among the 3 glucose groups (all $\mathrm{p}<0.05$ ). Hyperglycemia was frequent in patients with a low initial GCS score ( $\leq$ 8), hematoma volume $\geq 40 \mathrm{ml}$, and IVH (all $\mathrm{p}<0.05$ ). Patients in the SHG group had the highest WBC count, and those in the DM group had the highest HbAlc level (both $\mathrm{p}<0.05$ ). As compared with the NG group, both the DM and SHG groups had higher SBP, admission FBG level, and $\mathrm{Glu}_{\mathrm{SD}}$ and $\mathrm{Glu}_{\mathrm{CV}}$ for 7-day FBG (all $\mathrm{p}<0.05$ ). The dynamic changes in 7-day FBG in the 3 glucose groups are represented in Fig. 1. The level of FBG was higher in both the DM and SHG groups than in the NG group, with a downward trend.

\section{Study End Points \\ Clinical Characteristics}

In total, $46.7 \%$ of the ICH patients (171/366) had a poor outcome (mRS score $\geq 3$ ) at 30 days. The categories of age $\geq 65$ years, hypertension or MI, smoking, drinking, initial GCS score, hematoma location, IVH, hematoma volume, SBP, LDL-C, HDL-C, TG, admission FBG and HbAlc levels, WBC count, Glu ${ }_{\mathrm{SD}}$, and $\mathrm{Glu}_{\mathrm{CV}}$ differed be- tween the good and poor outcome groups (all p $<0.05$; Table 2).

The poor prognosis rates in the DM, SHG, and NG groups were $52.8 \%, 64.6 \%$, and $24.4 \%$, respectively (Fig. $2)$. The poor prognosis rate was highest in the SHG group as compared with the DM $(\mathrm{p}=0.045)$ and NG groups ( $\mathrm{p}<$ $0.001)$ and was significantly higher in the DM group than in the NG group $(\mathrm{p}<0.001)$. Overall mortality at 30 days was $16.1 \%$ for the entire cohort. Mortality was highest for the SHG group compared to the DM group (29.9\% vs $15.7 \%, \mathrm{p}=0.011)$ and the NG group $(3.1 \%, \mathrm{p}<0.001)$, and mortality was significantly higher for the DM group than the NG group $(\mathrm{p}<0.001)$.

An independent risk factor for a poor outcome in $\mathrm{ICH}$ patients was SHG (OR 2.62, 95\% CI 1.07-6.44) but not DM (1.69, 0.64-4.43; Table 3). Poor prognosis was associated with an increased FBG level on admission (OR $1.13,95 \%$ CI 1.05-1.22). Other predictors were an age $\geq$ 65 years, initial GCS score $\leq 8$, brainstem hematoma, and hematoma volume $\geq 20 \mathrm{ml}$ (all $\mathrm{p}<0.05$ ).

\section{Association Between GV and Outcome}

On separately adding $\mathrm{Glu}_{\mathrm{SD}}$ and $\mathrm{Glu}_{\mathrm{CV}}$ to the $\mathrm{Glu}_{\mathrm{SD}}$ and $\mathrm{Glu}_{\mathrm{CV}}$ models, respectively, based on the significant variables on bivariate analysis, we found that an independent risk factor for a poor outcome was a high level of $\mathrm{Glu}_{\mathrm{SD}}$ (OR 1.54, 95\% CI 1.19-1.99) or $\mathrm{Glu}_{\mathrm{CV}}(1.05,1.02-1.09)$; the WBC count was newly included in the model, and admission FBG level was excluded (Table 4). An age $\geq 65$ years, initial GCS score $\leq 8$, brainstem hematoma, and hematoma volume $\geq 40 \mathrm{ml}$ were still predictors of a poor outcome (all $\mathrm{p}<0.05$ ).

On stratification by glucose group, all risk factors in the entire cohort (that is, age, initial GCS score, hematoma location, hematoma volume, IVH, WBC count, and $\mathrm{Glu}_{\mathrm{SD}}$ ) associated with 30-day functional outcome were included in the $\mathrm{Glu}_{\mathrm{SD}}$ model. Risk factors for a poor outcome were a high $\mathrm{Glu}_{\mathrm{SD}}(\mathrm{OR} 1.94,95 \%$ CI 1.13-3.34) in the DM subset and a high WBC count $(1.22,1.07-1.40)$ in the SHG subset. An age $\geq 65$ years and large hematoma volume were still risk factors for a poor outcome in all subsets; brainstem hematoma and IVH were significant predictors in the DM and SHG subsets; and initial GCS score $\leq 8$ was a predictor of a poor outcome in the DM and NG subsets (all $\mathrm{p}<0.05$ ).

A similar analysis was performed for the $\mathrm{Glu}_{\mathrm{CV}}$ model. Here too risk factors for a poor outcome were a high $\mathrm{Glu}_{\mathrm{CV}}$ (OR 1.14, 95\% CI 1.04-1.26) in the DM subset and a high WBC count $(1.22,1.07-1.39)$ in the SHG subset. An age $\geq$ 65 years and hematoma volume $\geq 40 \mathrm{ml}$ remained predictors of a poor outcome in all subsets (Table 4).

\section{Assessing Prediction Models}

The AUC was 0.860 (95\% CI $0.823-0.898$ ) for the original logistic model, $0.929(0.902-0.956)$ for the $\mathrm{Glu}_{\mathrm{SD}}$ model, and $0.932(0.906-0.958)$ for the $\mathrm{Glu}_{\mathrm{CV}}$ model (Fig. 3). The AUC for the $\mathrm{Glu}_{\mathrm{SD}}$ or $\mathrm{Glu}_{\mathrm{CV}}$ model was greater than that for the original model in predicting a poor outcome; thus, adding GV for 7-day FBG to the model improved prediction of the 30-day functional outcome for patients with acute $\mathrm{ICH}$. 
TABLE 1. Baseline clinical characteristics of 366 patients with $\mathrm{ICH}$, according to glucose group

\begin{tabular}{|c|c|c|c|c|c|}
\hline Variable & Total $(n=366)$ & $\mathrm{DM}(\mathrm{n}=108)$ & SHG $(n=127)$ & $N G(n=131)$ & $p$ Value ${ }^{*}$ \\
\hline Age $\geq 65$ yrs & $156(42.6)$ & $53(49.1)$ & $49(38.6)$ & $54(41.2)$ & 0.248 \\
\hline Males & $217(59.3)$ & $63(58.3)$ & $71(55.9)$ & $83(63.4)$ & 0.463 \\
\hline \multicolumn{6}{|l|}{ Previous disease } \\
\hline Hypertension & $271(74.0)$ & $96(88.9)$ & $91(71.6) \dagger$ & $84(64.1) \dagger$ & $<0.001$ \\
\hline $\mathrm{Ml}$ & $102(27.9)$ & $31(28.7)$ & $36(28.3)$ & $35(26.7)$ & 0.933 \\
\hline Smoking & $166(45.4)$ & $47(43.5)$ & $57(44.9)$ & $62(47.3)$ & 0.834 \\
\hline Drinking & $114(31.1)$ & 39 (36.1) & $41(32.3)$ & $34(26.0)$ & 0.227 \\
\hline $\mathrm{SBP}$ in $\mathrm{mm} \mathrm{Hg}$ & $164.6 \pm 31.4$ & $171.9 \pm 28.7$ & $168.1 \pm 31.9$ & $155.7 \pm 31.2 \dagger \ddagger$ & $<0.001$ \\
\hline $\mathrm{DBP}$ in $\mathrm{mm} \mathrm{Hg}$ & $97.2 \pm 18.7$ & $97.9 \pm 16.5$ & $100.5 \pm 20.1$ & $93.4 \pm 18.5 \ddagger$ & 0.010 \\
\hline $\mathrm{PP}$ in $\mathrm{mm} \mathrm{Hg}$ & $67.6 \pm 20.8$ & $74.0 \pm 19.1$ & $67.7 \pm 22.4$ & $62.2 \pm 19.1$ & 0.356 \\
\hline Initial GCS score & & & & & $<0.001$ \\
\hline $13-15$ & $145(39.6)$ & $34(31.5)$ & $37(29.1) \dagger$ & $74(56.5) \dagger \ddagger$ & \\
\hline $9-12$ & $102(27.9)$ & $40(37.0)$ & $28(22.0) \dagger$ & $34(26.0) \dagger \ddagger$ & \\
\hline$\leq 8$ & $119(32.5)$ & $34(31.5)$ & $62(48.8) \dagger$ & $23(17.6) \dagger \ddagger$ & \\
\hline Hematoma location & & & & & 0.966 \\
\hline Basal ganglia & $151(41.2)$ & $44(40.7)$ & $54(42.5)$ & $53(40.4)$ & \\
\hline Lobar & $94(25.7)$ & $26(24.1)$ & $32(25.2)$ & $36(27.5)$ & \\
\hline Brainstem & $39(10.6)$ & $12(11.1)$ & $15(11.8)$ & $12(9.2)$ & \\
\hline Cerebellum & 48 (13.1) & $13(12.0)$ & $16(12.6)$ & $19(14.5)$ & \\
\hline Thalamus & $34(9.3)$ & $13(12.0)$ & $10(7.9)$ & $11(8.4)$ & \\
\hline Hematoma vol in $\mathrm{ml}$ & & & & & $<0.001$ \\
\hline$<20$ & $179(48.9)$ & $47(43.5)$ & $48(37.8) \dagger$ & $84(64.1) \dagger \ddagger$ & \\
\hline $20-40$ & $102(27.9)$ & $39(36.1)$ & $32(25.2)$ & $31(23.7) \dagger \ddagger$ & \\
\hline$\geq 40$ & $85(23.2)$ & $22(20.4)$ & $47(37.0)$ & $16(12.2) \dagger \ddagger$ & \\
\hline IVH & $189(51.6)$ & $57(52.8)$ & $83(65.4)$ & $49(37.4) \dagger \ddagger$ & $<0.001$ \\
\hline WBC count in $10^{9} / \mathrm{L}$ & $12.6 \pm 7.0$ & $11.9 \pm 5.3$ & $14.5 \pm 10.2 \dagger$ & $11.4 \pm 4.6 \ddagger$ & 0.002 \\
\hline $\mathrm{TC}$ in $\mathrm{mmol} / \mathrm{L}$ & $4.8 \pm 1.3$ & $5.2 \pm 1.7$ & $4.8 \pm 1.2$ & $4.6 \pm 1.2 \dagger$ & 0.023 \\
\hline LDL-C in $\mathrm{mmol} / \mathrm{L}$ & $3.0 \pm 1.4$ & $3.1 \pm 1.4$ & $2.8 \pm 1.5$ & $2.9 \pm 1.2$ & 0.427 \\
\hline $\mathrm{HDL}-\mathrm{C}$ in $\mathrm{mmol} / \mathrm{L}$ & $1.1 \pm 0.5$ & $1.1 \pm 0.4$ & $1.1 \pm 0.6$ & $1.1 \pm 0.4$ & 0.645 \\
\hline $\mathrm{TG}$ in $\mathrm{mmol} / \mathrm{L}$ & $1.5 \pm 1.4$ & $1.7 \pm 1.6$ & $1.2 \pm 1.1 \dagger$ & $1.4 \pm 1.3$ & 0.011 \\
\hline Admission FBG level in $\mathrm{mmol} / \mathrm{L}$ & $8.7 \pm 4.2$ & $11.3 \pm 4.5$ & $10.2 \pm 3.7$ & $5.2 \pm 0.9 \dagger \ddagger$ & $<0.001$ \\
\hline Admission HbAlc level in \% & $6.5 \pm 1.4$ & $7.8 \pm 1.9$ & $6.0 \pm 0.3 \dagger$ & $5.7 \pm 0.2 \dagger$ & $<0.001$ \\
\hline $\mathrm{Glu}_{\mathrm{SD}}$ in $\mathrm{mmol} / \mathrm{L}$ & $1.9 \pm 1.5$ & $2.7 \pm 1.6$ & $2.4 \pm 1.3$ & $0.7 \pm 0.3 † \ddagger$ & $<0.001$ \\
\hline $\mathrm{Glu}_{\mathrm{cV}}$ in $\%$ & $22.5 \pm 11.6$ & $27.5 \pm 11.7$ & $27.4 \pm 11.1$ & $13.74 \pm 5.0 \dagger \ddagger$ & $<0.001$ \\
\hline
\end{tabular}

$\mathrm{n}=$ number of patients; $\mathrm{PP}=$ pulse pressure.

Data are expressed as the mean \pm SD or as number (\%). Boldface type indicates statistical significance.

* Comparison among the DM, SHG, and NG groups.

$\dagger p<0.05$, compared with the DM group.

$\ddagger p<0.05$, compared with the SHG group.

\section{Discussion}

Hyperglycemia has been found to be associated with a poor prognosis in $\mathrm{ICH}$, creating much attention among clinical scientists. ${ }^{2,3,14,32,33}$ However, there is not enough emphasis on distinguishing between SHG and DM among ICH patients in the clinic. Moreover, the study of the correlation of continuous glucose monitoring and GV with the prognosis of ICH has not been performed. The current study may be the first to focus on the functional outcome associated with continuous glucose monitoring in ICH. We monitored the FBG level on admission and for 7 continuous days after admission in patients with acute-onset
$\mathrm{ICH}$. We investigated the associations among admission hyperglycemia, fluctuation in the continuous 7-day FBG level, and 30-day functional outcome.

\section{Hyperglycemia and Outcome After ICH}

We found that $64.2 \%$ of ICH patients had hyperglycemia at admission, which included $29.5 \%$ of patients in the SHG group and $34.7 \%$ in the DM group. We found that patients with a low initial GCS score, large hematoma volume, and IVH on admission frequently had hyperglycemia. Moreover, a high admission FBG level was an independent risk factor for an early (30-day) poor outcome in acute ICH, 


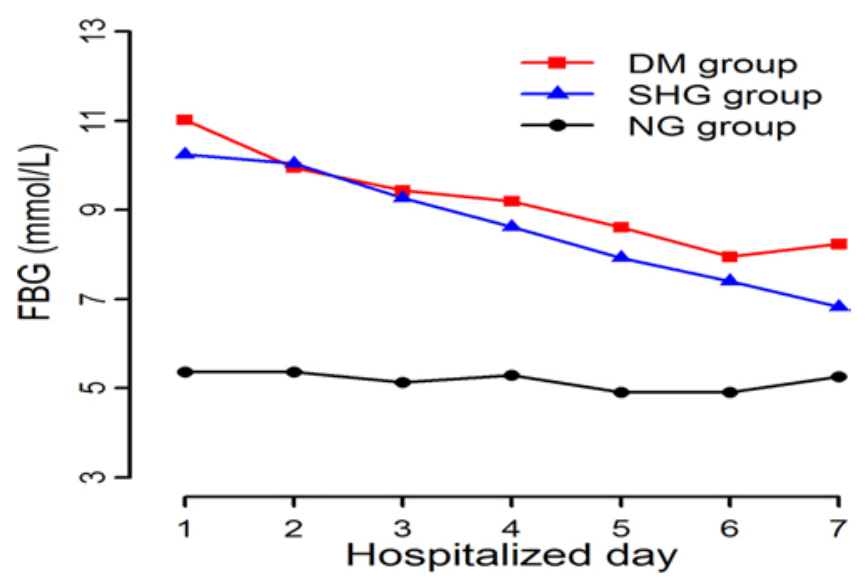

FIG. 1. Dynamic changes in 7-day FBG level in 3 glucose groups of hospitalized patients with $\mathrm{ICH}$. Figure is available in color online only.

and patients with SHG had a higher mortality and poorer prognosis rate than those with DM. A possible reason is that ICH patients with SHG had lower initial GCS scores, larger hematoma volumes, higher WBC counts, and IVH more often than the patients with DM or normal blood glucose. Related literature has shown that hyperglycemia substantially affects neurological functional recovery and prognosis in $\mathrm{ICH}$, regardless of whether the hyperglycemia is caused by diabetes or not, ${ }^{13}$ although DM can be characterized by chronic sustained hyperglycemia and the influence of the stress reaction may not be severe.

A study in Finland reported that DM predicted a poor prognosis and an early death in $\mathrm{ICH}$ and that admission hyperglycemia was not a risk factor for a poor functional outcome, although the study did not distinguish hyperglycemia in undiagnosed DM from that in SHG by measuring HbAlc level. ${ }^{35}$ With its unique application value, HbAlc is widely considered the gold standard for DM diagnosis, and hyperglycemia according to this value in undiagnosed DM can affect the analysis of functional outcome. ${ }^{8,37} \mathrm{We}$ measured the HbAlc level and found that $15.3 \%$ of $\mathrm{ICH}$ patients had newly diagnosed DM, which corresponded well with the $12 \%-25 \%$ reported by Clement and colleagues. ${ }^{6}$ Moreover, we found that a high FBG level on admission was associated with a 30-day poor functional outcome for ICH patients, particularly those with SHG.

Generally, glucose management for SHG and DM is similar in the acute setting but different later. Glucose management in the enrolled patients with ICH included glucose control, anti-infection agents, nutrient support, treatment of primary disease, and prevention of complications, strategies mainly based on the guidelines of the American Heart Association ${ }^{17}$ and the standards of medical care in DM. ${ }^{1}$ Glucose control for DM and SHG was similar when the glucose level was $\geq 10.0 \mathrm{mmol} / \mathrm{L}$; that is, therapy with a dose of 1-2 $\mathrm{U}$ of insulin or more per hour via intravenous insulin pump was administered until the glucose level was decreased to $7.8-10.0 \mathrm{mmol} / \mathrm{L}$ for at least 2 days. However, when the glucose level was $<10.0$ $\mathrm{mmol} / \mathrm{L}$ in patients with $\mathrm{DM}$, hypoglycemic treatment via subcutaneous insulin injection or oral hypoglycemic agents was continued to keep the glucose level in the nor-
TABLE 2. Baseline clinical characteristics associated with 30-day functional outcome in $366 \mathrm{ICH}$ patients

\begin{tabular}{|c|c|c|c|}
\hline Variable & Good Outcome & Poor Outcome & $p$ Value \\
\hline No. of patients & $195(53.3)$ & $171(46.7)$ & \\
\hline Age $\geq 65$ yrs & $63(32.3)$ & $93(54.4)$ & $<0.001$ \\
\hline Males & $112(57.4)$ & $105(61.4)$ & 0.457 \\
\hline \multicolumn{4}{|l|}{ Previous disease } \\
\hline Hypertension & $128(65.6)$ & $143(83.6)$ & $<0.001$ \\
\hline $\mathrm{Ml}$ & $44(22.6)$ & $58(33.9)$ & 0.016 \\
\hline Smoking & $76(39.0)$ & $90(52.6)$ & 0.006 \\
\hline Drinking & $44(22.6)$ & $70(40.9)$ & $<0.001$ \\
\hline $\mathrm{SBP}(\mathrm{mm} \mathrm{Hg})$ & $158.2 \pm 31.2$ & $171.8 \pm 30.3$ & $<0.001$ \\
\hline $\mathrm{DBP}(\mathrm{mm} \mathrm{Hg})$ & $94.5 \pm 16.9$ & $100.2 \pm 20.1$ & 0.063 \\
\hline $\mathrm{PP}(\mathrm{mm} \mathrm{Hg})$ & $64.1 \pm 20.3$ & $71.6 \pm 20.7$ & 0.051 \\
\hline Initial GCS score & & & $<0.001$ \\
\hline $13-15$ & $117(60.0)$ & $28(16.4)$ & \\
\hline $9-12$ & $61(31.3)$ & $41(24.0)$ & \\
\hline$\leq 8$ & $17(8.7)$ & $102(59.6)$ & \\
\hline Hematoma location & & & $<0.001$ \\
\hline Basal ganglia & $74(38.0)$ & $77(45.0)$ & \\
\hline Lobar & $63(32.3)$ & $31(18.1)$ & \\
\hline Brainstem & $8(4.1)$ & $31(18.1)$ & \\
\hline Cerebellum & $31(15.9)$ & $17(9.9)$ & \\
\hline Thalamus & $19(9.7)$ & $15(8.8)$ & \\
\hline Hematoma vol in $\mathrm{ml}$ & & & $<0.001$ \\
\hline$<20$ & $139(71.3)$ & $40(23.4)$ & \\
\hline $20-40$ & $39(20.0)$ & $63(36.8)$ & \\
\hline$\geq 40$ & $17(8.7)$ & $68(39.8)$ & \\
\hline IVH & $58(29.7)$ & $131(76.6)$ & $<0.001$ \\
\hline Admission FBG in $\mathrm{mmol} / \mathrm{L}$ & $7.5 \pm 3.4$ & $10.16 \pm 4.71$ & $<0.001$ \\
\hline Admission $\mathrm{HbAlc}$ in \% & $6.2 \pm 0.4$ & $6.8 \pm 1.8$ & 0.002 \\
\hline WBC $(10 \% / L)$ & $11.0 \pm 4.4$ & $14.4 \pm 9.3$ & $<0.001$ \\
\hline TC (mmol/L) & $4.9 \pm 1.5$ & $4.6 \pm 1.2$ & 0.530 \\
\hline LDL-C in mmol/L & $3.2 \pm 1.3$ & $2.7 \pm 1.4$ & $<0.001$ \\
\hline $\mathrm{HDL}-\mathrm{C}$ in $\mathrm{mmol} / \mathrm{L}$ & $1.2 \pm 0.4$ & $1.1 \pm 0.5$ & 0.015 \\
\hline $\mathrm{TG}$ in $\mathrm{mmol} / \mathrm{L}$ & $1.6 \pm 1.5$ & $1.3 \pm 1.2$ & 0.030 \\
\hline $\mathrm{Glu}_{\mathrm{SD}}$ in $\mathrm{mmol} / \mathrm{L}$ & $1.4 \pm 1.1$ & $2.5 \pm 1.6$ & $<0.001$ \\
\hline $\mathrm{Glu}_{\mathrm{CV}}$ in $\%$ & $19.5 \pm 10.1$ & $26.0 \pm 12.3$ & $<0.001$ \\
\hline Glucose groups & & & $<0.001$ \\
\hline NG & $99(50.8)$ & $32(18.7)$ & \\
\hline SHG & $45(23.1)$ & $82(48.0)$ & \\
\hline DM & $51(26.2)$ & $57(33.3)$ & \\
\hline
\end{tabular}

Data are expressed as the mean \pm standard deviation or as number $(\%)$. Boldface type indicates statistical significance.

mal range (4.4-6.1 mmol/L; diet and exercise can also be suggested); glucose levels only needed to be monitored in the patients with SHG.

\section{Glycemic Mechanism of Outcome}

We found a high proportion of ICH patients with acute hyperglycemia on admission, and SHG predicted a poor 


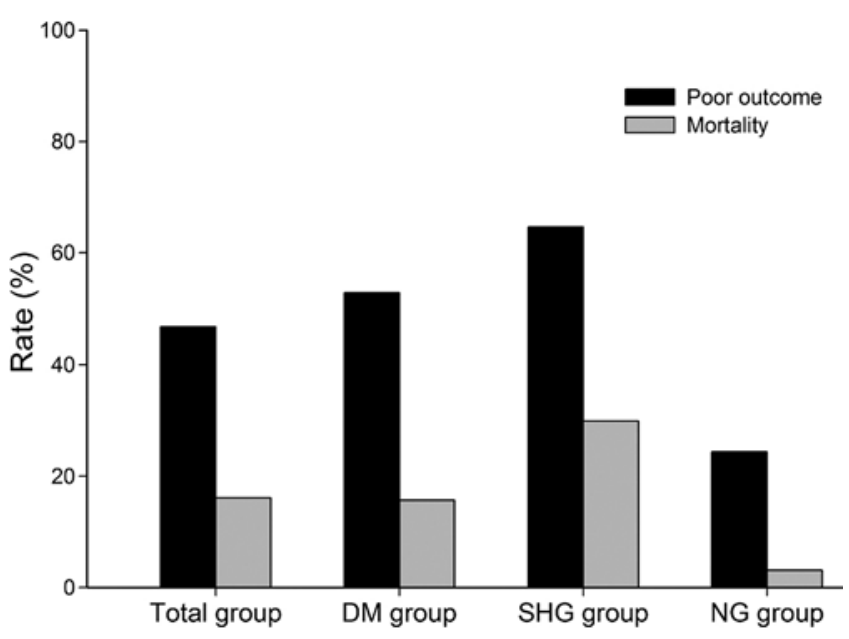

FIG. 2. Poor prognosis and mortality rate at 30 days in 3 glucose groups of hospitalized ICH patients.

functional outcome. Hyperglycemia induces an inflammatory response and promotes hemoglobin, ferroheme, and iron release after red blood cell lysis, ${ }^{12}$ and inflammation progresses in response to various stimuli to produce inflammatory signaling via activated microglia, subsequently releasing proinflammatory cytokines and chemokines that attract peripheral inflammatory infiltrates. ${ }^{41}$ Furthermore, the inflammatory process seems to enhance glucose toxicity in brain tissue, which also leads to metabolic dysregulation and secondary brain injury. ${ }^{36}$

The pathophysiological mechanisms of hyperglycemia are different between SHG and DM. Stress hyperglycemia is usually defined as hyperglycemia resolving spontaneously after the dissipation of acute illness. It represents a transient hyperglycemia lasting for a few days or weeks in patients without previous evidence of DM, and it is probably related to the primary disease, underlying type of disease, severity of disease, and stage of illness. With timely and appropriate treatment of the primary disease, effects of the stress reaction such as the release of catecholamines, glucagon, and cortisol may be effectively reduced, thus possibly decreasing the SHG level. ${ }^{8}$ Stress hyperglycemia is the body's stress response when a stimulus is greater than the body can tolerate; SHG is thereby generated by the change in homeostasis and neuroendocrine derangements. ${ }^{8}$ During the response, high levels of inflammatory cytokines such as TNF- $\alpha$ and IL- 6 are produced simultaneously, which results in injury to vessel endothelial cells, vessel structure, and the blood-brain barrier and leads to hemorrhagic infarct conversion. ${ }^{10}$ In contrast, the hyperglycemia in DM mainly results from a combination of insulin resistance and/or $\beta$-cell secretory defects ${ }^{1}$ and may take years to develop. Glycemic control in DM is mainly through stimulating the release of insulin or increasing the sensitivity of insulin. ${ }^{5}$

\section{A Protective Role for GV}

Recently, the GV that refers to fluctuations in glucose values ${ }^{25}$ has been proposed to be implicated in the diseaseassociated process of dysglycemia and a marker of glycemic control. ${ }^{29}$ Several studies have demonstrated that
TABLE 3. Multivariate analysis of independent predictors of 30 day poor outcome after ICH (original model)

\begin{tabular}{lcc}
\hline \multicolumn{1}{c}{ Variable } & OR $(95 \% \mathrm{Cl})$ & $\mathrm{p}$ Value \\
\hline Age $\geq 65$ yrs & $4.63(2.35-9.09)$ & $<0.001$ \\
\hline Initial GCS score & & $<0.001$ \\
\hline $13-15$ & 1.00 & \\
\hline $9-12$ & $1.17(0.53-2.54)$ & 0.700 \\
\hline$\leq 8$ & $7.09(2.98-16.82)$ & $<0.001$ \\
\hline Hematoma location & & $<0.001$ \\
\hline Basal ganglia & 1.00 & \\
\hline Lobar & $0.86(0.36-2.02)$ & 0.720 \\
\hline Brainstem & $23.68(6.51-86.16)$ & $<0.001$ \\
\hline Cerebellum & $1.19(0.43-3.25)$ & 0.738 \\
\hline Thalamus & $0.60(0.20-1.81)$ & 0.365 \\
\hline Hematoma vol in ml & & $<0.001$ \\
\hline$<20$ & 1.00 & \\
\hline $20-40$ & $6.52(2.93-14.47)$ & $<0.001$ \\
\hline$\geq 40$ & $7.14(2.80-18.26)$ & $<0.001$ \\
\hline IVH & $5.14(2.54-10.42)$ & $<0.001$ \\
\hline Admission FBG level & $1.13(1.05-1.22)$ & 0.002 \\
\hline Glucose group & & 0.012 \\
\hline NG & 1.00 & 0.036 \\
\hline SHG & $2.62(1.07-6.44)$ & 0.287 \\
\hline DM & $1.69(0.64-4.43)$ & \\
\hline S & & \\
\hline
\end{tabular}

Boldface type indicates statistical significance.

increased GV is negatively associated with a poor prognosis and an early death in critically ill patients, ${ }^{9}, 19$ and in patients with congestive heart failure. ${ }^{7}$ We found GV to be an independent risk factor for a poor prognosis in acuteonset ICH, especially in patients with DM. Furthermore, after adjusting for other related variables, both our $\mathrm{Glu}_{\mathrm{SD}}$ and $\mathrm{Glu}_{\mathrm{CV}}$ models, as compared to our original model, specifically predicted a poor prognosis with no significant difference between the $\mathrm{Glu}_{\mathrm{SD}}$ and $\mathrm{Glu}_{\mathrm{CV}}$ models. This finding did not agree with the results of Mendez et al., who reported that the SD of glucose was a better metric than CV. ${ }^{22}$

The ICH patients with DM and greater GV had wide fluctuations in glucose levels and poor glycemic control. Although we did not find DM to be an independent risk factor for a poor prognosis in $\mathrm{ICH}$, the DM patients with greater GV tended to have a poor outcome, which means the stress reaction also existed in the patients. However, distinguishing between SHG and DM is difficult in the clinic; thus, GV may be a valuable marker to reflect the stress reaction from severe primary disease and excessive inflammation. Therefore, GV could be a valuable marker for effective glycemic control and outcome in ICH patients with DM. It is important to improve the prognosis in ICH patients with DM by strengthening the management of glucose. Glycemic variability is still not a readily available or well-used metric in ICH in the clinic, ${ }^{21}$ and more comprehensive research on this factor is needed.

\section{Study Advantages}

There are certain advantages in our work. First, by ob- 


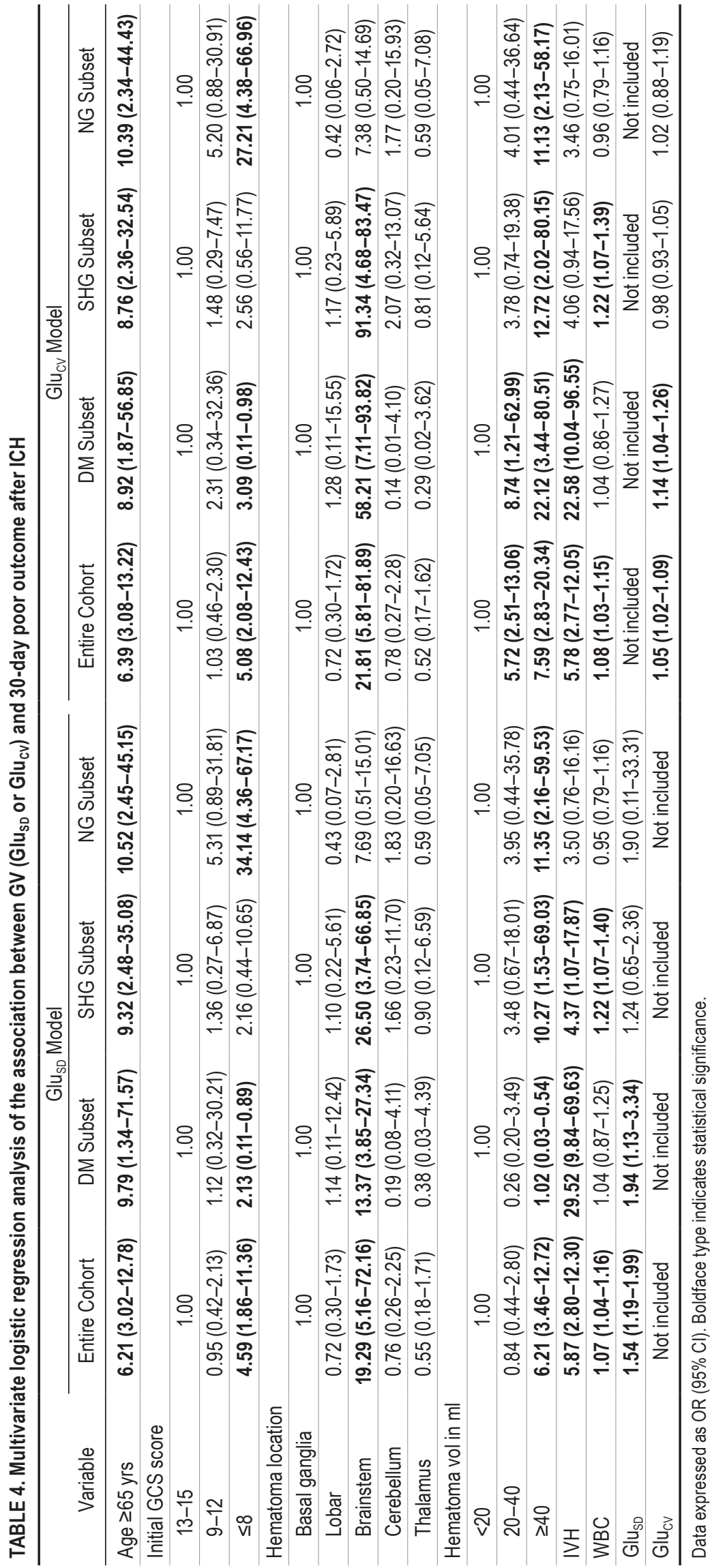




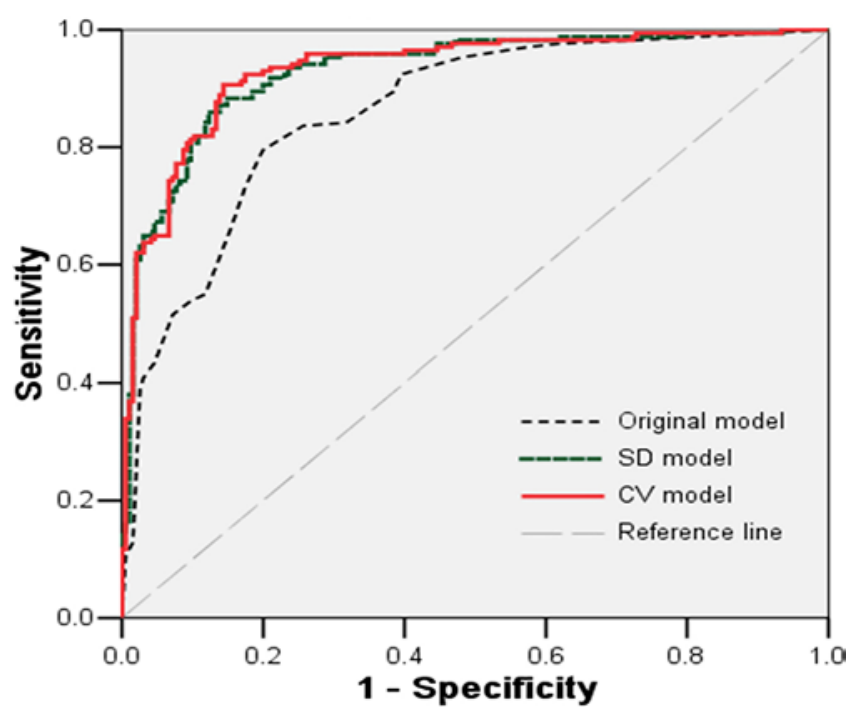

FIG. 3. Receiver operating characteristic curves for the original, $\mathrm{Glu}_{\mathrm{SD}}$ $(\mathrm{SD})$, and $\mathrm{Glu}_{\mathrm{CV}}(\mathrm{CV})$ models for predicting 30-day poor outcome in $\mathrm{ICH}$. Figure is available in color online only.

serving ICH patients in regular hospital units rather than the intensive care unit, we provided a novel view of the implication of GV for these specific patients. Second, by relying on both medical history and an examination of the HbAlc level for nondiabetic patients, rather than basing our observations only on medical history, we could determine whether hyperglycemia was associated with DM or SHG. Third, we collected FBG data at admission and with 7-day continuous monitoring in order to observe dysglycemia immediately, thereby avoiding influential factors of food metabolism. Fourth, we analyzed admission FBG level and GV over 7 days of continuous monitoring as well as other factors as they related to functional outcome in ICH through multivariate analysis. We eliminated the influence of other risk factors to better understand the relationship between glycemic index and prognosis. In brief, the study provided an improved understanding of hyperglycemia and GV in ICH that could help to elucidate the pathophysiology of ICH and lead to more effective management.

\section{Study Limitations}

Several limitations are acknowledged. First, we did not collect data on factors such as nutritional status, fluids, and time of administration of insulin, which may affect the assessed GV. Second, we did not attempt to answer whether early insulin treatment for hyperglycemia could be beneficial because our patients were not observing strict glycemic control. Third, we did not evaluate other glycemic indexes of GV such as mean amplitude of glycemic excursion and mean absolute glucose rate of change, which may indicate that our results are unilateral. Further studies should consider other glycemic indexes of GV.

\section{Conclusions}

Stress hyperglycemia may be associated with increased mortality and a poor outcome in $\mathrm{ICH}$, and increased GV may be independently associated with a poor outcome, particularly in ICH patients with DM. Both $\mathrm{Glu}_{\mathrm{SD}}$ and $\mathrm{Glu}_{\mathrm{CV}}$ improved the prediction of 30-day functional outcome in acute ICH.

\section{Acknowledgments}

This study was supported by grants from the Department of Education, Guangdong Government under the Top-tier University Development Scheme for Research and Control of Infectious Diseases (Grant Nos. 2015022 and 2015023) and the Science and Technology Plans of Shenzhen (Grant Nos. JCYJ201504033000426 and JCYJ20150403150555632). We thank Laura Smales (BioMedEditing, Toronto, Canada) for English language editing.

\section{References}

1. American Diabetes Association: (2) Classification and diagnosis of diabetes. Diabetes Care 38 (Suppl):S8-S16, 2015

2. Appelboom G, Piazza MA, Hwang BY, Carpenter A, Bruce SS, Mayer S, et al: Severity of intraventricular extension correlates with level of admission glucose after intracerebral hemorrhage. Stroke 42:1883-1888, 2011

3. Béjot Y, Aboa-Eboulé C, Hervieu M, Jacquin A, Osseby GV, Rouaud $\mathrm{O}$, et al: The deleterious effect of admission hyperglycemia on survival and functional outcome in patients with intracerebral hemorrhage. Stroke 43:243-245, 2012

4. Bloch RF: Interobserver agreement for the assessment of handicap in stroke patients. Stroke 19:1448, 1988

5. Brownlee M: The pathobiology of diabetic complications: a unifying mechanism. Diabetes 54:1615-1625, 2005

6. Clement S, Braithwaite SS, Magee MF, Ahmann A, Smith EP, Schafer RG, et al: Management of diabetes and hyperglycemia in hospitals. Diabetes Care 27:553-591, 2004 (Erratum in Diabetes Care 27:856, 2004)

7. Dungan KM, Binkley P, Nagaraja HN, Schuster D, Osei K: The effect of glycaemic control and glycaemic variability on mortality in patients hospitalized with congestive heart failure. Diabetes Metab Res Rev 27:85-93, 2011

8. Dungan KM, Braithwaite SS, Preiser JC: Stress hyperglycaemia. Lancet 373:1798-1807, 2009

9. Egi M, Bellomo R, Stachowski E, French CJ, Hart G: Variability of blood glucose concentration and short-term mortality in critically ill patients. Anesthesiology 105:244-252, 2006

10. Esposito K, Nappo F, Marfella R, Giugliano G, Giugliano F, Ciotola M, et al: Inflammatory cytokine concentrations are acutely increased by hyperglycemia in humans: role of oxidative stress. Circulation 106:2067-2072, 2002

11. Feigin VL, Forouzanfar MH, Krishnamurthi R, Mensah GA, Connor M, Bennett DA, et al: Global and regional burden of stroke during 1990-2010: findings from the Global Burden of Disease Study 2010. Lancet 383:245-254, 2014

12. Fogelholm R, Murros K, Rissanen A, Avikainen S: Admission blood glucose and short term survival in primary intracerebral haemorrhage: a population based study. J Neurol Neurosurg Psychiatry 76:349-353, 2005

13. Freire AX, Bridges L, Umpierrez GE, Kuhl D, Kitabchi AE: Admission hyperglycemia and other risk factors as predictors of hospital mortality in a medical ICU population. Chest 128:3109-3116, 2005

14. Godoy DA, Piñero GR, Svampa S, Papa F, Di Napoli M: Hyperglycemia and short-term outcome in patients with spontaneous intracerebral hemorrhage. Neurocrit Care 9:217-229, 2008

15. Han J, Lee HK, Cho TG, Moon JG, Kim CH: Management and outcome of spontaneous cerebellar hemorrhage. J Cerebrovasc Endovasc Neurosurg 17:185-193, 2015

16. Hanley JA, McNeil BJ: The meaning and use of the area under a receiver operating characteristic (ROC) curve. Radiology 143:29-36, 1982 
17. Hemphill JC III, Greenberg SM, Anderson CS, Becker K, Bendok BR, Cushman M, et al: Guidelines for the management of spontaneous intracerebral hemorrhage: a guideline for healthcare professionals from the American Heart Association/American Stroke Association. Stroke 46:2032-2060, 2015

18. Kothari RU, Brott T, Broderick JP, Barsan WG, Sauerbeck LR, Zuccarello M, et al: The ABCs of measuring intracerebral hemorrhage volumes. Stroke 27:1304-1305, 1996

19. Krinsley JS: Glycemic variability: a strong independent predictor of mortality in critically ill patients. Crit Care Med 36:3008-3013, 2008

20. Lovelock CE, Molyneux AJ, Rothwell PM: Change in incidence and aetiology of intracerebral haemorrhage in Oxfordshire, UK, between 1981 and 2006: a population-based study. Lancet Neurol 6:487-493, 2007

21. Martin WG, Galligan J, Simpson S Jr, Greenaway T, Burgess $\mathrm{J}$ : Admission blood glucose predicts mortality and length of stay in patients admitted through the emergency department. Intern Med J 45:916-924, 2015

22. Mendez CE, Mok KT, Ata A, Tanenberg RJ, Calles-Escandon J, Umpierrez GE: Increased glycemic variability is independently associated with length of stay and mortality in noncritically ill hospitalized patients. Diabetes Care 36:4091-4097, 2013

23. Meretoja A, Strbian D, Putaala J, Curtze S, Haapaniemi E, Mustanoja S, et al: SMASH-U: a proposal for etiologic classification of intracerebral hemorrhage. Stroke 43:2592-2597, 2012

24. Monnier L, Colette C, Owens DR: Glycemic variability: the third component of the dysglycemia in diabetes. Is it important? How to measure it? J Diabetes Sci Technol 2:10941100,2008

25. Monnier L, Mas E, Ginet C, Michel F, Villon L, Cristol JP, et al: Activation of oxidative stress by acute glucose fluctuations compared with sustained chronic hyperglycemia in patients with type 2 diabetes. JAMA 295:1681-1687, 2006

26. Palm F, Henschke N, Wolf J, Zimmer K, Safer A, Schröder $\mathrm{RJ}$, et al: Intracerebral haemorrhage in a population-based stroke registry (LuSSt): incidence, aetiology, functional outcome and mortality. J Neurol 260:2541-2550, 2013

27. Piironen K, Putaala J, Rosso C, Samson Y: Glucose and acute stroke: evidence for an interlude. Stroke 43:898-902, 2012

28. Rodbard D: Characterizing accuracy and precision of glucose sensors and meters. J Diabetes Sci Technol 8:980-985, 2014

29. Rodbard D: New and improved methods to characterize glycemic variability using continuous glucose monitoring. Diabetes Technol Ther 11:551-565, 2009

30. Sacco RL, Kasner SE, Broderick JP, Caplan LR, Connors JJ, Culebras A, et al: An updated definition of stroke for the 21st century: a statement for healthcare professionals from the American Heart Association/American Stroke Association. Stroke 44:2064-2089, 2013

31. Siegelaar SE, Holleman F, Hoekstra JB, DeVries JH: Glucose variability; does it matter? Endocr Rev 31:171-182, 2010

32. Stead LG, Jain A, Bellolio MF, Odufuye A, Gilmore RM, Rabinstein A, et al: Emergency Department hyperglyce- mia as a predictor of early mortality and worse functional outcome after intracerebral hemorrhage. Neurocrit Care 13:67-74, 2010

33. Tapia-Pérez JH, Gehring S, Zilke R, Schneider T: Effect of increased glucose levels on short-term outcome in hypertensive spontaneous intracerebral hemorrhage. Clin Neurol Neurosurg 118:37-43, 2014

34. Teasdale G, Jennett B: Assessment of coma and impaired consciousness. A practical scale. Lancet 2:81-84, 1974

35. Tetri S, Juvela S, Saloheimo P, Pyhtinen J, Hillbom M: Hypertension and diabetes as predictors of early death after spontaneous intracerebral hemorrhage. J Neurosurg 110:411-417, 2009

36. Wang J: Preclinical and clinical research on inflammation after intracerebral hemorrhage. Prog Neurobiol 92:463-477, 2010

37. Wexler DJ, Nathan DM, Grant RW, Regan S, Van Leuvan AL, Cagliero E: Prevalence of elevated hemoglobin A1c among patients admitted to the hospital without a diagnosis of diabetes. J Clin Endocrinol Metab 93:4238-4244, 2008

38. Whitworth JA: 2003 World Health Organization (WHO)/International Society of Hypertension (ISH) statement on management of hypertension. J Hypertens 21:1983-1992, 2003

39. Wilson JT, Hareendran A, Grant M, Baird T, Schulz UG, Muir KW, et al: Improving the assessment of outcomes in stroke: use of a structured interview to assign grades on the modified Rankin Scale. Stroke 33:2243-2246, 2002

40. Yang G, Wang Y, Zeng Y, Gao GF, Liang X, Zhou M, et al: Rapid health transition in China, 1990-2010: findings from the Global Burden of Disease Study 2010. Lancet 381:19872015, 2013

41. Zhou Y, Wang Y, Wang J, Anne Stetler R, Yang QW: Inflammation in intracerebral hemorrhage: from mechanisms to clinical translation. Prog Neurobiol 115:25-44, 2014

\section{Disclosures}

The authors report no conflict of interest concerning the materials and methods used in this study or the finding specified in this paper.

\section{Author Contributions}

Conception and design: QY Zhang. Acquisition of data: Y Wu, Wang. Analysis and interpretation of data: Y Wu, Ding. Drafting the article: QY Zhang, Y Wu. Critically revising the article: QY Zhang, Y Wu. Reviewed submitted version of manuscript: QY Zhang, Y Wu. Approved the final version of the manuscript on behalf of all authors: QY Zhang. Statistical analysis: Ding, Wen, Dong. Administrative/technical/material support: QY Zhang, J

Wu, SC Zhang. Study supervision: QY Zhang.

\section{Correspondence}

Qing-Ying Zhang, Department of Preventive Medicine, Shantou University Medical College, 22 Xinling Rd., Shantou, Guangdong 515041, China. email: qyzhang@stu.edu.cn. 